\title{
22
}

\section{A Comprehensive Methodology for Factory Modelling}

\author{
K. Popplewell and R. Bell \\ Department of Manufacturing Engineering, \\ Loughborough University of Technology, \\ Loughborough, Leicestershire, LE11 3TU, United Kingdom. \\ Phone: (44) 01509 222925; Fax: (44) 01509267725 \\ E-mail:K.Popplewell@lut.ac.uk
}

\begin{abstract}
The view on factory modelling presented in this paper is that there is a need for a family of design tools which can be used to support a methodology which will result in the design and improvement of performance of factories, achieved in a satisfactory timescale, at acceptable cost, and yielding effective results.

The methodology embraces issues which range from the initial establishment of business strategy and its interactions with the manufacturing strategy and financial strategy models of a business through the use of approximate modelling methods which are capable of rapid expansion in detail, to the realisation of dynamic outputs as an important viewpoint. The process can be extended down the modelling range by offering interfaces to lower level tools, many of which are already available.

In the authors' view the methodology and the tools it supports form a key business process technology.
\end{abstract}

\section{Keywords}

Factory design, approximate modelling, multi-view modelling, generic models

\section{INTRODUCTION}

In rapidly changing markets, with the stimulus of multi-national, and multi-business enterprises, it is becoming the norm for a typical factory to have to frequently change its operating practices to meet the dictates of business pressures. This is in part caused by the increasing tendency for enterprises to consist of multi-business groupings: changes in the business status of the enterprise and its markets frequently call for change in the structure of the enterprise, and in particular, its constituent factories. Evidence has been accumulating to support this point, and furthermore shows that the engineering industry increasingly splits the design and manufacturing functions between different sites or indeed different countries. 


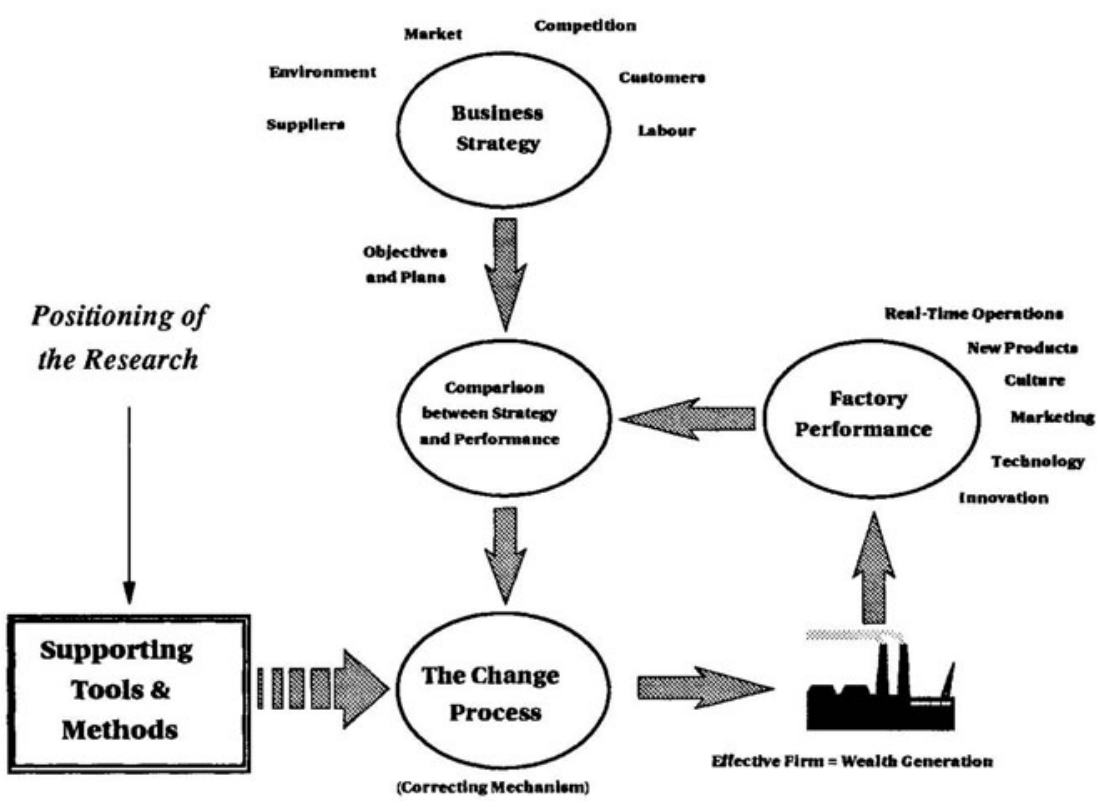

Figure 1 : The business performance enhancement cycle.

There is increasing evidence that these multi-business enterprises depend not only on the information networks controlling and supporting individual businesses but also on the network at the enterprise level linking the activities of the those businesses. It is important therefore for methodologies and tools supporting the alignment of business process with business strategy to be at least capable of modelling the factory activities and information networks concurrently. In some cases the required re-engineering could centre initially either on the reconfiguration of the factory activities or conversely on the information network.

Factory design can either involve the design of a totally new green field site, or be targeted on significant changes in an existing business (ie. business performance enhancement) where the speed and impact of the changes are at a premium. In the contemporary scene reconfiguration of the business is more frequently, though not exclusively, encountered than the task of green field site design.

The challenges posed cannot be met by traditional methods which are typified by potentially inefficient and unreliable decision making, and unsatisfactory information transfer from senior business managers to middle managers who must take responsibility for implementing change. Further, the methodologies and tools currently available are unacceptably slow and limited in their usefulness. We believe there is a strong case for methodologies and software tools to support rapid and competent reconfiguration of factories. Factories can and should be designed as effectively as it is now accepted that products can be designed, and the reported research leads to methods and software tools invaluable in making factory design a systematic and reliable activity. The concept of factory design is to some extent a radical one; many 
experienced innovators whose techniques are centred on identifying and improving business processes might be surprised by the proposition that factory design is a realisable goal.

As depicted in Figure 1, the industrial change process discussed above can be regarded, in classical control language, as a regulator system where the reference is the business strategy and the output is business performance. If this model is accepted then a change mechanism is needed to complete the closed loop. This change process is a now well established part of industrial life which normally takes the form of a team effort or the work of external consultants to prescribe and implement the necessary change in factory performance. This activity needs proven methodologies supported by software tools: the research reported here is targeted on this area and constitutes a major extension of the facilities which are currently available to the agents of change.

\section{STATE OF THE ART}

Recent research work on enterprise modelling has made significant contributions on both concept and method. Fox (1993) has developed what he terms a "common-sense" enterprise model, from which he claims that "we lack the software that would enable computers to provide access to information and support decision making across the organisations". Mize's (1992) group explored enterprise rationalisation, concluding that individual management system and production system rationalisation cannot enhance enterprise competitiveness unless both systems are integrated, in line with a vision of improvement at higher levels. Work by Mujtaba (1994) and Malhotra (1992) provides a method by which an enterprise at implementation level can be simulated. The results obtained by Mayer (1991), Cook (1992) and Scheer (1992) are competitive to this research: Mayer uses situation classification frameworks and site specification frameworks to select modelling tools. In contrast Cook uses Taguchi methods to build models, and Scheer shows a preference for information modelling as the core of enterprise design.

There are three apparent competitive lines of thought in contemporary research: the first is based on the use of highly developed, prescriptive, generic enterprise structures. The most dominant examples of this approach are typified by the CIM-OSA architecture currently centred in the AMICE and VOICE projects in the Esprit programme. The concept of the virtual factory model, as typified by the work of VTT in Finland, is a fascinating aid to product design though not a direct competitor to this work. Reference must also be made to the long established and widely used methodology which has been introduced and developed by GRAI group. The approach underpinning this research is significantly different to each of these in that it is assumed always that methodology and business tools associated with business process re-engineering will encourage an uninhibited approach to specifying business strategy objectives and the factories which are designed to realise them. One major competitive feature is the ability to incorporate additional business performance viewpoints relevant to particular aspects of a factory design.

Beside the seminal work of Hammer and Champy (1993), there are a number of publications in the field of business process re-engineering which are relevant, and in particular it is noted that Rigby (1993), Davenport (1990, 1993), and Tunalv (1992) as well as De Toni (1992) have studied the total concept of the business process and how it should be updated; a number of publications dealing with specific methodologies to support the business process 
engineering activity have been reported by Bennett (1992) and Turnbull (1992).

In considering work done on an international scale, note has been taken of emerging radical views on future trends in manufacturing. The work of Warnecke (1993) on fractal factories presents stimulating challenge to contemporary business process thinking. Japanese views on the post-mass production paradigm present a technologically oriented solution, whilst Hirsch (1994) considers, as in Figure 2 a classification of production management paradigms. Thinking in the USA, typified by work reported by Goldman on agile manufacturing, dominated by the impact of software engineering

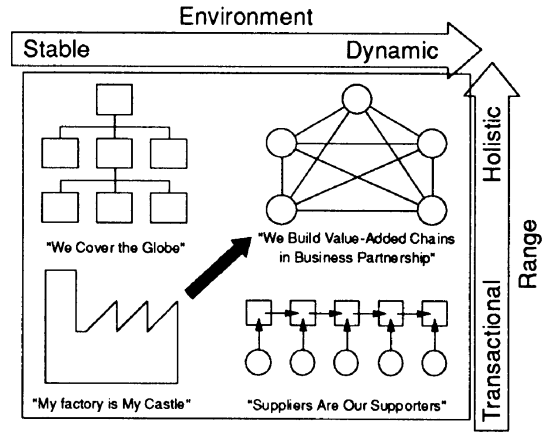

Figure 2 : Classification of paradigms for production management systems (Hirsch 1994). constitutes a a typical North American approach.

The biggest international challenges to thought are the astonishing developments which are taking place in industry. Companies drawing upon the support of substantial use of IT are regrouping into global partnerships. For example the A.B.B. Group consists of a small executive group based in Zurich which controls 5000 profit centres in 130 countries; this re-grouped company is only 5 years old. The authors have gained significant insight in to Japanese practice. However it is considered that this does not represent the plateau of maximum performance as it is noted that the Japanese themselves are anxious to embrace new methodologies and have an increasing interest in software tools. The Japanese experience is not unique: similar evidence is available in Europe and the USA. In the U.K., Lucas Group's approach to manufacturing systems engineering and to factory improvement now offers both a proven track record and distinctive methodology.

\section{A TOP-DOWN METHODOLOGY}

The structure of this methodology is strongly influenced by the authors' interactions with industry in a number of teaching company and funded research projects. It is essential that the link between top management and middle management - the decision makers and the enablers should be kept as fluid and as accurate as possible; in turn the middle managers must lead teams working on the updating of particular activity areas who in turn will require software support including ready interfacing to other proprietary lower level tools in order to complete their tasks effectively.

The emphasis should be placed, as in Figure 3, on a top down modelling approach which is adequately fast to be responsive to the rate of change of decisions which can be realistically expected from top management. An important part of this view is the use of approximate modelling methods coupled with dynamic output which assumes that the models are focused on the changing situation rather than extensive historical evidence gained within the business.

A core issue in this research has been the establishment of a consistent link between changes 
in business strategy and the manufacturing performance of the business. The following four areas of decision making knowledge have been captured by a matrix based modelling approach similar to that of Inamoto (1990 and 1991): business strategy, product design strategy, strategic manufacturing evaluation, and financial constraints. Major characteristics of the Strategic Manufacturing Decision Support (SMDS) tool are the consideration of the time dimension, the flexible integration of multi-disciplinary factors, and easy extension to include other perspectives. This decision aid is being researched in a spreadsheet environment on a PC host so that it can be low cost, simple to use, and capable of tailoring to specific companies' applications.

The complexity of a factory calls for a description approach which can be used to produce a complete but approximate factory model. The model should be complete because all the crucial aspects of the factory should be

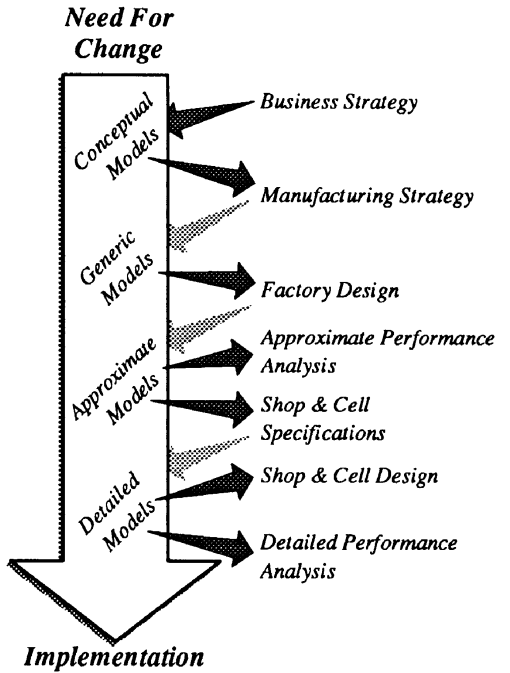

Figure 3 : A top-down methodology for factory modelling. captured, whilst at the same time it should be approximate because all extraneous details should be ignored.

Whilst the level down to which approximate models are developed will vary from business to business, the effective limit of approximate modelling is the point where a completely satisfactory set of requirements and constraints can be delivered to middle managers, who then may be given the freedom to carry out the redesign within their activity areas. At this level the enablers may readily be able to turn to the use of either proprietary low level modelling tools which they already employ, or other design procedures which allow them to meet the requirements placed upon them.

Recent research has delivered some of the tools needed in applying this methodology, and gives confidence that the remainder can be realised. The ease of modelling is achieved both by the use of a proven user interface coupled with the use of approximate modelling methods, and by a powerful extension to speed of modelling made possible by the introduction of the generic modelling concept. The potentially more important attribute in this concept is the use of multiview modelling which allows those doing the detailed re-engineering work to make initial access by more than one view.

\section{MULTI-VIEW MODELS}

The search for appropriate methodologies in business process design has lead to the introduction of a number of paradigms [eg. Hirsch et al., Jovane, Wenzel et al.] to meet a range of related but disparate needs. A major theme in this research is that a paradigm can be integrated into a business modelling software tool which can support a range of model views in a way which harmonises a range of user requirements. Each view allows concentration on a 


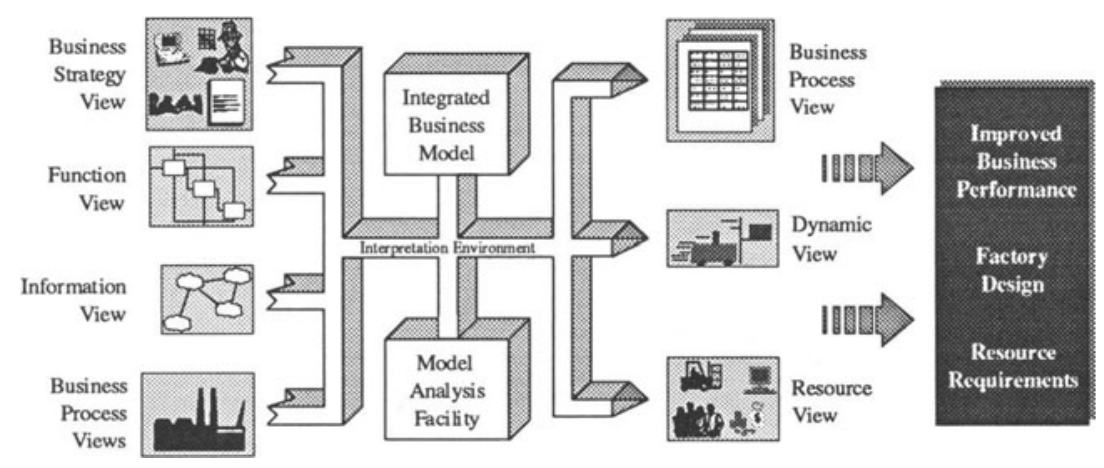

Figure 4 : Integrated multi-view modelling.

particular aspect of modelling, which corresponds to working with a particular conventional modelling paradigm. Thus, for example, in studying the information structures used by the business to specify the business information system, the modeller interacts with an information view of the model, whilst to predict the business' performance he would interact with the dynamic view. However both views share much of the model content, which appears in, and must be entered into, the integrated model only once. In contrast, the sequential use of conventional modelling methods for these purposes requires considerable duplication of model building.

Figure 4 depicts such a multi-view interpretation and identifies two categories of view. Some views are primarily model-building views, in one of which model building would normally commence, and whose output is essentially a presentation of the model as constructed. The function view of the activity structure of the business is such a view. In, contrast, other views, exemplified by the dynamic view, whilst requiring additional information in their construction, would not normally constitute a starting point for modelling, but would provide deeper analysis of the model as their outputs.

The need for integration is highlighted by the degree commonality of information incorporated in the individual models: for example a functional view of the system, identifying the activities which are necessary to achieving business strategy, also requires access to a definition of the structures of information which must flow between the transforming activities. The construction of independent models to meet the needs of each view of the business process necessitates duplication of model definition, potentially to a very considerable degree.

Research has established the feasibility of building integrated multi-view models of this nature, including in demonstrator software a function view, a dynamic view and an initial form of an information view. A taxonomy of further views (eg. a resource view) which may be of value in business process design is being investigated, with a view to constructing a reference model of views identifying applicability and relationship between views. 


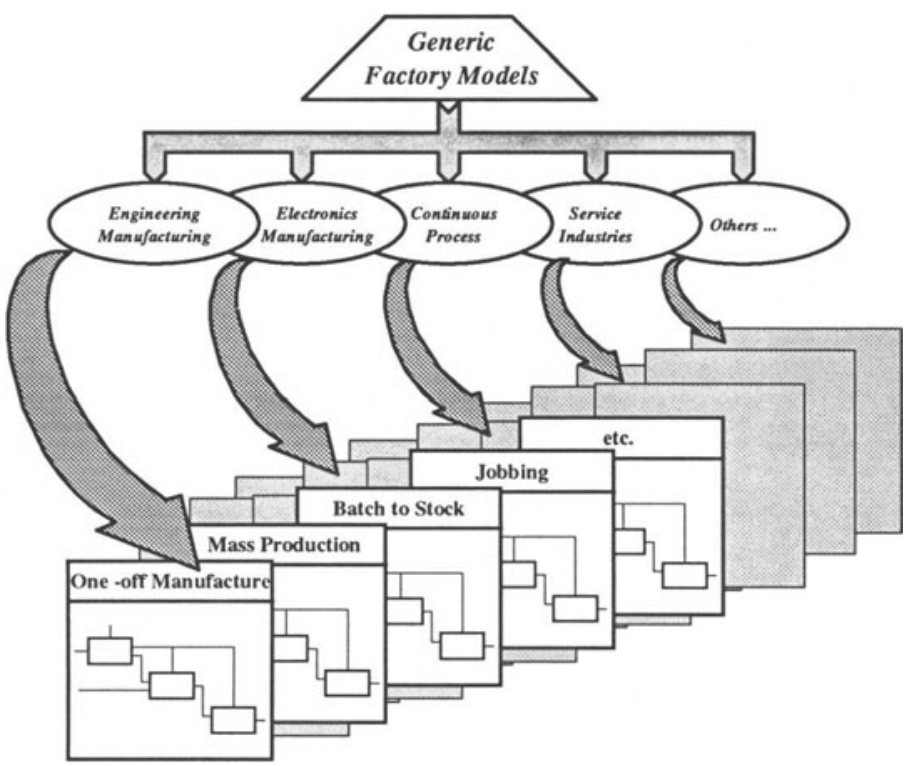

Figure 5 : Generic modelling.

\section{GENERIC MODELLING}

Generic models provide a starting point for model-building. Each contains, in a generalised form, the common features of a business system operating a particular manufacturing philosophy in a business sector. Initial modelling then takes the form of identifying the generic model which most nearly matches the desired business system; the generic model can then be rapidly modified to meet a particular need.

Generic models can fulfil two distinct roles in supporting business process re-engineering, with its emphasis on the speed of the activity. The task of building a model from a blank sheet is necessarily protracted, and yet it is the authors' experience that common themes run through the structures of successful companies operating in related markets. Thus an understanding of commonality establishes the degree to which generic models can provide a starting point for modelling. This provides accelerated modelling simply because the volume of work involved in specialising a generic model, selected as the closest available to the developing business process design, is much reduced.

To be of value, a range of generic models must be available not only to correspond to different business sectors, but to provide a range of starting points within each sector; they must also allow users to model the global manufacturing interactions which are now coming strongly into view, and must assist users to seek the flatter structures which will be necessary for greater speed of market response. The Warnecke concept of the fractal factory appears to be highly relevant to this work. 
Furthermore we see that work reported by Carrie $(1993,1994)$ et al. has developed ideas on identification of business processes which have a record or probability of performing successfully. Such ideas, incorporated into a set of generic models have the advantage of guiding design to employ best practice. It is however important to emphasise that generic models are not prescriptive: their purposes are to be supportive in rapid model building, and encouraging in adoption of best practice. In building a particular model a generic model will be selected and specialised without restriction.

\section{CONCLUDING DISCUSSION}

This methodology addresses the need to be able to support design or re-design of factories by modelling in parallel with the natural progression of design decision-making. It is embodies the essential link between the strategic aspirations of the enterprise and initial decisions on the manufacturing philosophies to be adopted and the requirements which must be met by the factory if those strategic aspirations are to be fulfilled. Software demonstrating the feasibility of capturing these links has been successfully researched, and will provide a specification for subsequent stages of factory design.

Approximate models must then be used in design of the structure of the factory, encouraging analysis of the activities the factory must perform, the flows of information and material which these activities generate or require, and the performance requirements of each activity. It is not possible to use more conventional modelling of detailed activities at this stage of factory design, since no detailed decisions are even contemplated at this point in the decision making process. Real decisions on the major functions of the factory (including both manufacturing processes and support functions such as product design, production engineering, production control etc.) are made before consideration of detailed plant and personnel investment starts, and approximate modelling allows support of these decisions at the time they are made, typically in the first month of the factory design process.

Software demonstrators of both approximate and multi-view modelling for three selected views have been successfully implemented. This shows the feasibility of integrating a range of model views, and it is significant that collaborating companies have used these demonstrators and the methodology in factory re-design projects following completion of research activity in the companies.

Both the methodology and commercial developments of the software demonstrators are able to offer enhanced support of the progressively more frequent process of factory design. The top-down approach coupled with use of generic models, allows modelling to provide support on realistic timescales. The use of integrated multiple views allows the model to be examined for a variety of purposes without the need to build several separate models embodying much of the same content.

The feasibility of applying and supporting such a methodology has been established. There is now a need to extend its range of applicability in number of ways. Firstly, developments in both hardware and software technology now make it possible to implement the ideas described above in efficient ways. Much use can be made of established modelling interfaces, and of links from approximate modelling to existing commercially available tools for detailed process modelling. This would provide the modelling software industry with enhanced products, meeting new customer needs, and would provide their customers with supported software to 
help satisfy their established need to advance manufacturing into competitive future forms.

The range of views considered to date has been sufficient to demonstrate that multi-view integration is possible and valuable, and the views considered have their own merits. There is now need to appraise the range of possible views which might be relevant to factory design, and the feasibility of their integration within the same structure. A reference model of modelling views, based on industry sector, business strategies and manufacturing technology would provide a guide not only to the views which should be integrated, but to those which a particular user of the methodology would need to address.

Related to this is the need to extend the range of generic models to include the range of industry sectors, and business types within sector which can benefit from application of the methodology.

\section{REFERENCES}

Bennett, D., Forester, P. and Hassard, J. (1992) Market-driven Strategies and the Decision of Flexible Production Systems: Evidence from the Electronics Industry" International Journal of Operations and Production Management, 12:2, 25-37.

Carrie, A.S. and MacIntosh, R. (1993) Improving Integration in Manufacturing Systems, IFIP Transactions on Advances in Production Management Systems, (eds. Pappas, I.A. and Tatsiopoulos, I.P.) North Holland, Amsterdam.

Carrie, A.S. and MacIntosh, R. (1994) A structured approach to process redesign, Proceedings of the BPICS Annual Technical Conference, Birmingham, 153-167.

Cook, H.E., (1992) Organizing Manufacturing Enterprise for Customer Satisfaction, in Manufacturing Systems, National Academy Press (ed. Heim, J.A. and Compton, W.D.), 116-127.

Davenport, T.H. (1990) The New Industrial Engineering Information Technology and Business Process Redesign, Sloan Management Review 31:4, 11-27.

Davenport, T.H. (1993) Process Innovation:Reengineering Work Through Information Technology. Harvard Business School Press

De Toni, A., Filippini R. and Forza C. (1992) Manufacturing Strategy in Global Markets: An Operations Management Model, International Journal of Operations and Production Management, 12:4, 7-18.

Fox, M.S. (1993) Issues in Enterprise Modelling, International Workshop on Intelligent Manufacturing Systems.

Goldman, S.L., Nagel, R. N., and Preiss, K. (1994) Agile competitors and virtual organisations. Van Nostrand Reinhold, New York.

Hirsch, B., Crom, S., Thoben, K.-D. and Kuhlman, T.(1994) New Manufacturing Paradigms Their Contribution to Improve Customer Satisfaction, Shorten Time-to-Market and Lengthen Time-in-Market, EITC '94, Brussels, 26-34.

Hammer, M. and Champy, J. (1993) Reengineering the Corporation - A Manifesto for Revolution. Nicholas Brealy Publishing, London.

Inamoto, A. (1990) Conceptual and Architectural Description on a Class of CIM Models, Proceedings of 1990 Japan-USA Symposium on Flexible Automation, Kyoto.

Inamoto, A. (1990) The Architecture of Integrated Factory Automation" Proceedings of 1990 IFAC World Congress. 
Inamoto, A. and Shirakura, T. (1991) Modelling of Factory Automation System by Objectoriented Approach, Proceedings of Ist IFAC Workshop on Algorithm and Architecture for Real-Time Control, Bangor.

Malhotra, R. and Jayaraman, S. (1992) An Integrated Framework for Enterprise Modeling, Journal of Manufacturing Systems, 11:6, 426-440.

Mayer, R.J. and Painter, M.K. (1991) Roadmap for Enterprise Integration, AUTOFACT '91, 7.1-7.26.

Mize, J.H., Pratt, D.B. and Farrington, P.A. (1992) System Integration: The Forcing Function for Enterprise Rationalization, in Proceedings of Manufacturing International '92 (ed. D.Durham), 117-126.

Mujtaba, M.S. (1994) Simulation Modelling of a Manufacturing Enterprise with Complex Material, Information and Control Flows, International Journal of Computer Integrated Manufacturing, 7:1, 29-46.

Rigby, D. (1993) The Secret History of Process Reengeneering, Planning Review, 21:2, 2427.

Scheer, A.W.(1992) Architecture of Integrated Information Systems: Foundations of Enterprise Modelling. Springer-Verlag, Berlin.

Tunalv, C. (1992) Manufacturing Strategy- Plans and Business Performance, International Journal of Operations. and Production Management, 12:3, 4-24.

Turnbull, G.K. and Fisher, E.S. (1992) Improving Manufacturing Competitiveness Through Strategic Analysis, in Manufacturing Systems, National Academy Press.

Warnecke, H.-J.(1993) The Fractal Company - A Revolution in Corporate Culture, SpringerVerlag, Berlin.

\section{BIOGRAPHIES}

R Bell: Appointed Professor of Manufacturing Technology at LUT 1978. Established research in flexible manufacturing systems with particular emphasis given to modelling methods for cell design. Contemporary research interests concerned with the role of product and manufacturing models in computer integrated engineering, concepts for factory modelling, and research into tool management systems. A major recent interest has been the international activities in IMS, being a member of the European and International Technical Committees throughout the feasibility study. Another major interest has been support for academic development under the aegis of the ODA and UN, with assignments in Brazil, Hong Kong, India, Mexico, Singapore, Sri Lanka and Turkey.

K. Popplewell: Joined LUT in 1985, after sixteen years' experience in manufacturing industry, particularly involving production management, production engineering and computer aided engineering projects. Contemporary research interests include factory modelling concepts, engineering moderation to drive concurrency in simultaneous engineering, and applications of hybrid artificial intelligence methods in support of cooperative project working. 